\title{
O ENSINO DE LÍNGUAS BASEADO EM TAREFAS NO ENSINO/ APRENDIZAGEM DA ESCRITA EM PORTUGUÊS LÍNGUA SEGUNDA - PROPOSTAS DIDÁTICAS
}

\author{
TASK-BASED LANGUAGE TEACHING ON THE TEACHING/ \\ LEARNING OF WRITING IN PORTUGUESE SECOND \\ LANGUAGE - DIDACTIC PROPOSALS
}

Jorge PINTO'

Resumo: O objetivo deste artigo é apresentar uma reflexão sobre o Ensino de Línguas Baseado em Tarefas (ELBT), por se considerar que poderá possibilitar o desenvolvimento mais eficaz da produção escrita. Existem vários tipos de tarefas, sendo o objetivo de cada uma resolver dada situação comunicativa, através de uma espontânea troca de sentidos, que tem relação com a vida real e a experiência dos alunos, despertando o seu interesse e aumentando o seu envolvimento na aprendizagem. Os principais problemas que os alunos enfrentam na escrita são: a seleção lexical adequada ao tema; a seleção dos tempos verbais adequados ao contexto; a ortografia e a pontuação corretas; a coerência e a coesão textuais. Como forma de ultrapassar estas dificuldades, propõe-se o ELBT. Assim, num primeiro momento, analisar-se-á a importância do ELBT no ensino das línguas segundas, em geral, e da escrita, em particular, e, num segundo, como parte de um estudo desenvolvido em três escolas secundárias da Praia - Cabo Verde, serão propostas tarefas testadas com êxito em sala de aula, em contexto de língua segunda. Os resultados parciais, baseados num questionário aplicado aos alunos que participaram no estudo, revelam que há maior envolvimento dos alunos nas tarefas de escrita e uma perceção de melhoria desta competência.

Palavras-chave: Português língua segunda. Ensino de línguas baseado em tarefas. Produção escrita.
Abstract: The main purpose of this article is to present a reflection on Task-Based Language Teaching (TBLT) because it is thought to allow more efficient and effective learning of the writing skills. There are several types of tasks whose goal is to solve a communicative situation through a spontaneous exchange of meanings, which has a relationship with real life and the student's experience, thus arousing their interest and increasing their involvement in learning. The main problems that students have to face when writing are an appropriate lexical selection regarding the topic; the selection of adequate verb tenses as far as the context is concerned; correct spelling and punctuation; textual coherence and cohesion. In order to overcome these difficulties, we propose the TBLT. So, at first, we will analyze the importance of TBLT both in the teaching of second languages, in general, and in writing, in particular. Then, as part of a study carried out in three secondary schools in Praia - Cabo Verde, it will be proposed tasks already successfully tested in the classroom, in a second language context. The partial results, based on a questionnaire applied to students who participated in the study, reveal that there is a greater involvement of students in writing tasks and a perception of an improvement in this competence.

Keywords: Portuguese second language. Task-based language teaching. Teaching of writing.

1 Universidade de Lisboa (UL), Lisboa, Portugal; jorgepinto@letras.ulisboa.pt; https://orcid.org/0000-0002-5583-880X 
- O ensino de línguas baseado em tarefas no ensino/aprendizagem da escrita em português língua segunda - propostas didáticas

\section{Introdução}

Os alunos aprendem de diferentes formas: vendo e ouvindo, refletindo e agindo, pensando de forma lógica e intuitiva... Logo, as abordagens e metodologias de ensino devem também variar, evoluindo e adaptando-se aos públicos-alvo.

O ensino de línguas baseado em tarefas (ELBT), cuja implementação tem sido advogada por diferentes autores (LONG, 1985; PRABHU, 1987; NUNAN, 1989; WILLIS, 1996; SKEHAN, 1998; BYGATE; SKEHAN; SWAIN, 2001; WILLIS; WILLIS, 2007), desde a década de 80 do século passado, veio dar resposta a uma melhor compreensão de como as línguas estrangeiras ou segundas são aprendidas, na tentativa de promover uma aprendizagem eficiente e eficaz de uma língua estrangeira (LE) ou língua segunda (L2). Através desta abordagem, faculta-se aos alunos material com o qual eles têm de se ocupar ativamente para atingir determinado objetivo ou concluir uma tarefa. O ELBT procura desenvolver a interlíngua dos alunos através da execução de uma tarefa, durante a qual realizam interações na LE ou L2.

No que a produção escrita diz respeito, é comum observarmos que se trata de um trabalho predominantemente individual e que os professores colocam a tónica na correção linguística da escrita dos alunos, proporcionando-lhes, assim, evidência negativa a maior parte do tempo. Tal abordagem dificulta a aprendizagem da escrita e provoca um desinteresse dos alunos por esta competência (ATKINSON, 2003). Contrariamente, o ELBT preconiza uma aprendizagem da produção escrita mais como um processo, com um propósito comunicativo, do que como um produto. O foco é a criatividade e a expressão pessoal do aluno, na sua interação com o outro. Escrever é entendido como um ato social (ATKINSON, op. cit.).

Neste sentido, este artigo tem por objetivo demonstrar que o ELBT é uma abordagem adequada para o ensino da escrita em português língua segunda (PL2), que pode proporcionar resultados mais eficazes na aprendizagem do que uma abordagem de carácter mais tradicional. Por conseguinte, apresentamos resultados parciais de um estudo realizado com três turmas, cada uma pertencente a uma das três escolas da cidade da Praia, em Cabo Verde. Após testadas as tarefas de escrita, durante um mês, consideramos fundamental verificar em que medida as reações dos alunos eram favoráveis (ou não) a esta nova forma de aprendizagem da língua, uma vez que não estavam habituados. Neste sentido, foram aplicados questionários a 104 alunos que nos deram feedback sobre as tarefas realizadas. Os resultados desses questionários permitiram perceber que as propostas didáticas avançadas podem ter impactos positivos na prática de ensino da escrita nas aulas de PL2. 


\section{O ensino de línguas baseado em tarefas na aprendizagem de línguas estrangeiras}

O ELBT é uma abordagem para ensinar LE ou L2 que coloca os alunos no centro da aprendizagem da língua, que usam para realizar tarefas, pedir informações, refletir e dar a opinião. O ELBT propõe tarefas como o principal componente das aulas de línguas, uma vez que estas proporcionam melhores condições de ativação dos processos de aquisição dos alunos e fazem com que estes progridam na aprendizagem da LE ou L2. A tarefa permite aos alunos compreenderem, trabalharem e interagirem na língua-alvo, sempre com um propósito comunicativo (NUNAN, op. cit.). Como refere Fotos (2002, p. 138, tradução nossa ${ }^{2}$ ), "a tarefa pode dar ao aluno um input na língua-alvo, rico em usos comunicativos de estruturas-alvo problemáticas, e a sua realização oferece oportunidades para o tipo de interação do aluno que promove a aquisição da língua; trata-se de oportunidades para produzir na língua-alvo e para receber feedback sobre as produções". Este feedback "permite que os alunos percebam a lacuna entre a língua-alvo que desejam produzir e a limitação da sua interlíngua atual" (ibidem, tradução nossa ${ }^{3}$ ).

Trata-se de uma abordagem que reúne em si um conjunto de ideias vindas da filosofia da educação, das teorias de aquisição de línguas estrangeiras, de estudos empíricos sobre estratégias educativas e das exigências da aprendizagem de línguas na sociedade atual.

Neste sentido, Nunan (2004, p. 35-37) determina sete princípios do ELBT:

(1) Scaffolding: as aulas e os materiais devem fornecer modelos de apoio dentro dos quais a aprendizagem acontece, dado que no início do processo de aprendizagem não se deve esperar que os alunos produzam estruturas ou usem construções que não foram explicitamente ensinadas.

(2) Precedências: dentro de uma aula, a tarefa deve crescer e construir-se sobre as anteriores. Este princípio impõe uma "história pedagógica" enquanto os alunos são guiados de etapa em etapa até o momento em que serão capazes de realizar a tarefa pedagógica final. Nas primeiras etapas, os alunos dedicam mais tempo às competências de receção (ouvir/ler) do que às de produção

\footnotetext{
2 No original: "task can supply the learner with target language input that is rich in communicative usages of problematic target structures, and task performance provides opportunities for the type of learner interaction suggested to promote language acquisition; that is opportunities to produce the target language and receive feedback on the productions".

3 No original: "enables learners to notice the gap between the target language they want to produce and the limitation of their current interlanguage".
} 
- O ensino de línguas baseado em tarefas no ensino/aprendizagem da escrita em português língua segunda - propostas didáticas

(falar/escrever). Posteriormente, dentro do ciclo da tarefa, são alteradas as proporções, passando a produção a ocupar mais tempo.

(3) Reciclagem: a reciclagem da língua maximiza as oportunidades da aprendizagem e ativa o princípio "orgânico" da aprendizagem, possibilitando aos alunos descobrirem itens da língua-alvo num conjunto de diferentes contextos, ambos linguísticos e experienciais.

(4) Aprendizagem ativa: os alunos aprendem melhor quando usam ativamente a língua-alvo. Isto significa que a maior parte do tempo deverá ser dedicada ao uso da língua nas mais diversas formas, desde, por exemplo, a prática de diálogos ao preenchimento de questionários. É essencial que seja o aluno a realizar o trabalho e não o professor.

(5) Integração: os alunos devem ser ensinados de modo a estabelecerem relações claras entre forma gramatical, função comunicativa e significação semântica. O maior desafio para a pedagogia é reintegrar os aspetos formais e funcionais da língua, explicitando para isso as relações sistémicas entre forma, função e conteúdo.

(6) Reproduzir para criar: nas tarefas reprodutivas, os alunos reproduzem modelos de língua fornecidos pelo professor, pelo manual ou por uma gravação. Essas tarefas são concebidas para dar aos alunos o domínio da forma, do sentido e da função, e criar uma base para as tarefas criativas. Nestas, os alunos combinam os elementos familiares, aprendidos, de diferentes formas.

(7) Reflexão: devem ser dadas oportunidades aos alunos para refletirem sobre o que aprenderam e sobre a correção com que estão a usar a língua.

O ELBT oferece algumas alternativas aos professores. Numa aula desenvolvida à base de tarefas, o professor não pré-determina necessariamente que aspetos da língua vão ser estudados, a aula centra-se numa tarefa principal e as questões linguísticas a estudar podem ser determinadas pelo que acontece na resolução dessa mesma tarefa pelos alunos.

Ao longo dos anos, foram surgindo diversas definições para o conceito tarefa, das quais destacamos algumas:

(1) "[...] uma atividade que requer que os alunos cheguem a um resultado a partir de determinada informação, através de um processo de pensamento, e que 
permite aos professores controlarem e regularem esse processo" (PRABHU, 1987, p. 17, tradução nossa4);

(2) "[...] uma atividade em que a língua-alvo é usada pelos alunos com um propósito comunicativo, a fim de alcançar um resultado" (WILLIS, 1996, p. 23, tradução nossa $\left.{ }^{5}\right)$;

(3) "Uma tarefa é um plano de trabalho que exige que os alunos processem a língua de forma pragmática para alcançar um resultado que possa ser avaliado em termos de se um correto ou apropriado conteúdo proposicional foi transmitido. Para isso, requer que eles deem atenção em primeiro ao significado e façam uso de seus próprios recursos linguísticos, embora a estrutura da tarefa possa conduzi-los a escolher formas específicas" (ELLIS, 2003, p. 16, tradução nossa ${ }^{6}$;

(4) "[...] um trabalho na sala de aula que envolve os alunos na compreensão, manipulação, produção ou interação na língua-alvo, enquanto a sua atenção encontra-se focada em mobilizar o seu conhecimento gramatical para expressar significados" (NUNAN, 2004, p. 4, tradução nossa?).

Assim, uma tarefa pode ser caracterizada como uma atividade (ou conjunto de atividades) de aprendizagem cujo objetivo é levar os alunos a transmitirem significados num contexto situacional específico, relacionado com o mundo que os rodeia, o que significa que eles necessitam manipular, produzir e interagir na língua-alvo, a fim de resolverem uma situação comunicativa. A tarefa proporciona um contexto, um motivo para adquirir a língua (VAN THIENEN, 2009).

O Conselho da Europa (2001, p. 218), no Quadro Europeu Comum de Referência $(Q E C R)$, refere esta contextualização das tarefas, esta situação real de comunicação, que funciona como um fator de motivação:

\footnotetext{
4 No original: "[...] an activity which required learners to arrive at an outcome from given information through some process of thought, and which allowed teachers to control and regulate that process".

5 No original: "[...] an activity in which the target language is used by the learners for a communicative purpose in order to achieve an outcome".

6 No original: "A task is a workplan that requires learners to process language pragmatically in order to achieve an outcome that can be evaluated in terms of whether the correct or appropriate propositional content has been conveyed. To this end, it requires them to give primary attention to meaning and to make use of their own linguistic resources, although the design of the task may predispose them to choose particular forms".

7 No original: "[...] a piece of classroom work that involves learners in comprehending, manipulating, producing or interacting in the target language while their attention is focused on mobilizing their grammatical knowledge in order to express meaning".
} 
- O ensino de línguas baseado em tarefas no ensino/aprendizagem da escrita em português língua segunda - propostas didáticas

As tarefas pedagógicas comunicativas (ao contrário dos exercícios que dão destaque especificamente à prática descontextualizada de formas) pretendem envolver ativamente os aprendentes numa comunicação real, são relevantes (aqui e agora no contexto formal de aprendizagem), são exigentes mas realizáveis (com manipulação da tarefa, quando necessário) e apresentam resultados identificáveis (e possivelmente outros, menos evidentes no imediato). As tarefas deste tipo podem envolver tarefas (intermediárias) 'metacognitivas', ou seja, a comunicação sobre a implementação da tarefa e a língua usada para a realizar.

As tarefas implicam processos cognitivos de seleção, raciocínio, classificação, organização e transformação da informação de uma forma de representação para outra (PRABHU, op. cit.). Estas fazem o sistema do aluno progredir, ativando os processos de aquisição (LONG; CROOKES, 1993). O ELBT entende o processo de aprendizagem como uma aprendizagem pela realização, pela experimentação; considera que é por se dedicar sobretudo ao sentido que o sistema do aluno é estimulado a desenvolver-se. Os preconizadores do ELBT consideram que a aprendizagem de uma língua é um processo psicolinguístico e não apenas linguístico e que deve envolver o aluno na construção do seu conhecimento (LONG; CROOKES, 1992), ao contrário do que acontecia nos currículos tradicionais.

Nunan (2004) propõe seis elementos (Figura 1) que, segundo ele, estão envolvidos na execução da tarefa: objetivos, input e procedimentos que são suportados pelos papéis do professor e do aluno e pela situação e contexto.

Figura 1. Modelo de tarefa

\begin{tabular}{|lllr|}
\hline Goals & $\longrightarrow$ & Task & Teacher role \\
Input & $\longrightarrow$ & & Learner role \\
Procedures & $\longrightarrow$ & & Settings \\
\hline
\end{tabular}

Fonte: Nunan (2004, p. 41)

Os objetivos são intenções gerais subjacentes a todas as tarefas de aprendizagem e têm por finalidade atingir resultados comunicativos, afetivos e cognitivos, ou ainda descrever diretamente o comportamento dos alunos e do professor. Os objetivos mais úteis são aqueles que se referem ao aluno, não ao professor, e aqueles que são redigidos 
do ponto de vista da competência observável. O input refere-se aos dados orais, escritos e visuais com os quais os alunos trabalham para completar a tarefa. Os procedimentos especificam o que os alunos vão fazer com o input que constitui o ponto de partida para a realização da tarefa de aprendizagem. Podemos analisar os procedimentos segundo a autenticidade (interações comunicativas autênticas fora da sala de aula) ou a nãoautenticidade, o foco na obtenção ou no uso de uma determinada competência e o foco no desenvolvimento da correção, da fluência ou do controlo.

O papel do aluno está ligado às estratégias de aprendizagem e ao tipo de tarefas a desenvolver. Nesta abordagem, o aluno passou a ser o elemento-chave da sua própria aprendizagem e participa ativamente nas aulas como executor, recetor, interveniente... Surge como um negociador que interage no grupo e como sendo responsável da sua aprendizagem e do desenvolvimento de estratégias para "aprender a aprender" (RICHARDS; ROGERS, 2001). No que toca ao papel do professor, Willis e Willis (2007) consideram que há seis papéis que um professor assume neste tipo de ensino:

(1) líder e organizador da atividade: a maior parte das tarefas inicia-se com a apresentação do tema pelo professor e organização da turma;

(2) gestor dos trabalhos dos grupos: o professor necessita de gerir bem este tipo de atividades (em grupo ou pares) para conseguir os melhores resultados dos alunos;

(3) facilitador: o professor deve encontrar o equilíbrio entre uma tarefa que proporcione o melhor tipo de desafio e a certeza de que os alunos são capazes de executá-la corretamente;

(4) motivador: é importante que o professor motive os alunos o mais possível, através de um feedback positivo e razoável;

(5) conhecedor da língua e conselheiro: ajudar os alunos com o sentido, o significado, interagindo com eles como alguém com um bom conhecimento da língua e uma maior experiência;

(6) professor de língua: há fases em que o professor tem de adotar o seu papel tradicional, explicando, demonstrando e focalizando na forma.

A situação e o contexto dizem respeito à tarefa em si, que pode ser desenvolvida individualmente, em pequeno ou grande grupo, e na totalidade ou parcialmente no exterior da sala de aula. Willis e Willis (op. cit.) são da opinião de que as tarefas devem ter em conta a envolvente social em que a língua é utilizada e permitir aos alunos tomarem consciência 
- O ensino de línguas baseado em tarefas no ensino/aprendizagem da escrita em português língua segunda - propostas didáticas

desta dimensão social. A estes fatores, os autores acrescentam a consciencialização dos alunos para a forma como a língua é construída, sobretudo o discurso oral espontâneo.

Skehan (1998) propõe cinco características-chave de uma tarefa para que seja considerada enquanto tal:

- o sentido está em primeiro lugar;

- não é dado aos alunos discurso de outras pessoas para reproduzirem;

- relação entre as tarefas e o mundo real;

- $\quad$ a realização e conclusão da tarefa são prioritárias;

- a avaliação da tarefa faz-se a partir dos resultados obtidos.

Segundo Skehan (1994), basicamente, existem três objetivos pedagógicos para as abordagens à base de tarefas: a exatidão, a complexidade/reestruturação e a fluência. A exatidão refere-se ao modo como bem é produzida a língua-alvo, tendo em conta as suas regras. A complexidade diz respeito à elaboração da língua produzida. O processo que permite ao aluno produzir uma linguagem cada vez mais complexa é a reestruturação. A fluência diz respeito à capacidade do aluno de falar em tempo real sem abusar das pausas ou das hesitações. O professor deve, portanto, recorrer a tarefas que permitam aos alunos enriquecer a sua interlíngua de uma forma natural e equilibrada.

De forma a cumprir esses três objetivos, muitas tarefas são realizadas segundo uma estrutura que foi sendo desenvolvida e provou ser eficiente. Essa estrutura apresenta-se em três fases de execução (WILLIS, op. cit.):

(1) Pré-tarefa: introdução do tema; negociação da tarefa e das modalidades de execução; ativação de alguns conteúdos linguísticos necessários;

(2) Tarefa: planificação; execução da tarefa; apresentação dos resultados;

(3) Pós-tarefa: foco na forma - estudo das estruturas, do léxico novo e resolução dos problemas linguísticos; feedback e avaliação.

Numa aula baseada em tarefas, o professor pode não pré-determinar os itens linguísticos a serem tratados, uma vez que a aula se centra na conclusão de uma tarefa central e esses itens a estudar são determinados pelo que acontece à medida que os alunos completam a tarefa. Embora o professor possa apresentar estruturas linguísticas na pré-tarefa, os alunos são livres para usar o que eles necessitam na realização da tarefa. Isto Ihes permite usar tudo o que já conhecem da língua-alvo e não ficar limitados a uma única 
construção. O professor pode aproveitar a fase de pós-tarefa para realizar, então, o foco na forma, sem que isso tenha interferido no desenvolvimento natural da tarefa.

Apesar dos aspetos positivos que se destacam no ELBT, desde os anos 80, altura em que atraiu atenção crescente de investigadores e formadores de professores, este ensino tem sido criticado por alguns autores, defensores do currículo estrutural e de abordagens tradicionais, como Bruton (2002a, 2002b), Seedhouse (1999, 2005), Sheen (1994), Swan (2005) e Widdowson (2003).

Os críticos argumentam contra a definição de tarefa considerando que "os critérios que são propostos como características definidoras das tarefas são... tão vagamente formulados... que não distinguem tarefas de outras atividades mais tradicionais na sala de aula" (WIDDOWSON, 2003, p. 126, tradução nossa ${ }^{8}$ ) ou que é impossível prever a atividade que resulta do desempenho de uma tarefa. Portanto, as tarefas não podem servir como unidades para planear um curso de línguas (SEEDHOUSE, 2005). No entanto, os critérios definidos por Ellis (2009, p. 223, tradução nossa ${ }^{9}$ ) para que uma atividade de ensino de línguas seja uma "tarefa" são muito claros e contradizem a posição de Widdowson:

(1) O foco principal deve ser o 'significado' (o que significa que os alunos devem preocupar-se principalmente com o processamento do significado semântico e pragmático dos enunciados).

(2) Deve haver algum tipo de 'lacuna' (ou seja, a necessidade de transmitir informações, expressar uma opinião ou inferir significado).

(3) Os alunos devem, em grande parte, depender de seus próprios recursos (linguísticos e não linguísticos) para concluir a atividade.

(4) Há um resultado claramente definido que não seja o uso da língua (isto é, a língua serve como meio para alcançar esse resultado, não como um fim em si mesma).

\footnotetext{
8 No original: "the criteria that are proposed as defining features of tasks are... so loosely formulated... that they do not distinguish tasks from other more traditional classroom activities.".

9 No original: "(1) The primary focus should be on 'meaning' (by which is meant that learners should be mainly concerned with processing the semantic and pragmatic meaning of utterances). (2) There should be some kind of 'gap' (i.e. a need to convey information, to express an opinion or to infer meaning). (3) Learners should largely have to rely on their own resources (linguistic and non-linguistic) in order to complete the activity. (4) There is a clearly defined outcome other than the use of language (i.e. the language serves as the means for achieving the outcome, not as an end in its own right)".
} 
- O ensino de línguas baseado em tarefas no ensino/aprendizagem da escrita em português língua segunda - propostas didáticas

Assim, o objetivo principal de uma tarefa é alcançar um resultado comunicativo, mas o objetivo de um exercício é demonstrar o uso correto de um conteúdo linguístico da língua-alvo (ELLIS, 2014).

Em resposta às críticas de Seedhouse, Ellis (2014) argumenta que se o objetivo passa por criar contextos para o uso de uma linguagem natural e para proporcionar uma aquisição incidental, então, sem dúvida, a previsão das atividades não é necessária. A previsão só importa se a intenção do professor for usar tarefas para ensinar os seus alunos com base num programa estrutural.

Widdowson também critica a ideia da autenticidade das tarefas, argumentando que o ELBT enfatiza em demasia o uso autêntico da língua, porque, no seu entender, os contextos da sala de aula nos quais a língua é geralmente aprendida são totalmente diferentes daqueles em que a língua é usada (WIDDOWSON, op. cit.). No entanto, concordamos com Long (2016), quando ele refere que o trabalho com tarefas que se aproximam do mundo real pode ser muito realista em salas de aula cujo ensino de línguas é baseado em tarefas. De facto, as tarefas têm uma relação pedagógica clara com as necessidades comunicativas do mundo real.

Outra crítica contra o ELBT é sobre o ensino da gramática. Sheen (op. cit.) e Swan (op. cit.) argumentam que no ensino de línguas baseado em tarefas não existe "nenhum programa de gramática". Na verdade, o que acontece é exatamente o oposto. Como Ellis (2014) alega, a atenção à gramática pode ser verificada em todas as fases de uma aula baseada no ensino por tarefas. Neste ensino, os itens linguísticos não só são tratados como são tratados de uma forma cientificamente mais válida do que acontece no currículo tradicional (LONG, 2016).

Um dos princípios metodológicos do ELBT é o foco na forma, no qual, segundo Long (1991), a comunicação continua a ser o objetivo central do ensino e a principal diferença é a tentativa de resolver problemas que surgem durante interação, focalizando brevemente a atenção sobre aspetos linguísticos. O foco na forma (realizações que incluem noções como consciousness raising, form-focused instruction, ou form-focused intervention) também pode incorporar as interações conversacionais modificadas, com a finalidade de tornar a mensagem compreensível, chamando a atenção dos alunos para as relações de forma, de sentido e de função da L2 (PICA, 2002).

Em suma, apesar de todas as críticas feitas ao ELBT, este ensino preocupa-se com o desenvolvimento da competência comunicativa dos alunos e com o foco na competência linguística contextualizada nos propósitos comunicativos da estrutura em questão, sugerida pelo foco na forma. O ELBT permite que os alunos compartilhem informações na 
língua-alvo com outros colegas, para interagir recriando situações reais de comunicação. Assim, a associação deste ensino com atividades fora da sala de aula pode promover um franco desenvolvimento da competência comunicativa dos alunos.

\section{O ensino da escrita por tarefas}

As tarefas, conforme referido na secção anterior, implicam mais os alunos nas atividades desenvolvidas nas aulas de língua estrangeira e centram-se mais no significado. Logo, defendemos que esta abordagem também se adequa e produz resultados mais eficazes no desenvolvimento da produção escrita. Como refere Cassany (2009), o ensino por tarefas, possuindo uma estrutura de atividades encadeadas voltadas para a obtenção de um produto final, facilita o uso dos diferentes tipos de funções escritas em diferentes fases do processo de tarefa.

No ELBT e particularmente no processo de ensino da escrita, os professores devem ter em atenção três aspetos: a análise das necessidades dos alunos, uma criteriosa seleção de materiais didáticos autênticos, o cuidado de envolver os alunos em atividades comunicativas significativas, afastando-se da abordagem frequentemente praticada de simples reprodução de modelos previamente fornecidos aos alunos e de análise linguística. Não queremos com isto dizer que esses modelos não devam ser dados e que o trabalho sobre a língua não deva ser feito, mas que deve haver espaço para que o aluno demonstre a sua capacidade criativa e desenvolva as suas estratégias para produzir um texto escrito, através do qual expresse as suas ideias e consiga fazer-se comunicar num contexto linguístico específico. Long e Crookes (1992) defendem isso mesmo, referindo que a tarefa facilita a apresentação de exemplos apropriados da língua-alvo aos alunos e proporciona diferentes oportunidades de compreensão e de produção com diferentes graus de complexidade.

O foco da tarefa é essencialmente na escrita em si e não na correção linguística. Pretende-se que os alunos possam explorar as suas ideias e selecionar o léxico que conhecem e consideram apropriado, com o intuito de se tornarem ativos. Os textos produzidos refletem a sua capacidade para resolver determinado problema retórico, o seu conhecimento dos objetivos comunicativos a cumprir, da situação comunicativa, do leitor e, ainda, do contexto da escrita. Trata-se, pois, do produto resultante de um processo sociocognitivo que exige capacidades cognitivas complexas e que põe em prática as competências linguística e cultural dos alunos. Este conjunto de operações linguísticas e cognitivas desenvolve-se de forma dinâmica, interativa, cíclica e em diferentes níveis de análise (objetivos pragmáticos do texto, ideias para o conteúdo do mesmo, estruturas 
- O ensino de línguas baseado em tarefas no ensino/aprendizagem da escrita em português língua segunda - propostas didáticas

linguísticas...). Estas operações podem ocorrer, durante a tarefa de produção escrita, a qualquer momento e sem uma ordem específica (CASSANY, op. cit.).

Um aspeto positivo do ELBT é a possibilidade de os alunos trabalharem em grupos, desenvolvendo o seu trabalho com um objetivo comum, num espírito de colaboração. O trabalho cooperativo implica que haja uma estrutura organizativa que promova a realização conjunta de uma determinada tarefa; cada membro permite ao outro falar e contribuir e considera as suas contribuições, tendo em vista um objetivo comum (KOHONEN, 1992). Pensa-se que tal interação facilita a aquisição de língua uma vez que os alunos têm de trabalhar para se fazerem entender uns aos outros e se exprimirem (LARSENFREEMAN, 1986). As tarefas interativas são, por vezes, consideradas particularmente benéficas, especialmente as do tipo de procura de informação, nas quais os alunos têm de dar informações a colegas que não a têm (PICA; KANAGY; FALODUN, 1993). O professor deve fomentar a cooperação durante a tarefa de produção escrita, promovendo a escrita em pares ou em pequeno grupo, a revisão dos textos entre os alunos, a partilha de opiniões...

Nesta abordagem, durante a escrita, os alunos são livres para explorar as suas ideias, sem se preocuparem demasiadamente com erros ortográficos, o uso de modos e tempos verbais, vocabulário específico. Esse trabalho, também necessário, obviamente, cabe na última fase, a da pós-tarefa, em que alunos e professor se dedicam a correções e melhoria dos textos produzidos. O foco na forma surge neste momento permitindo chamar, agora, a atenção dos alunos para questões de âmbito linguístico que de outra forma poderiam passar despercebidas e não serem aprendidas (LONG, 1991). No entanto, segundo este autor (op. cit.), a comunicação permanece como o objetivo central de toda a tarefa, sendo o foco na forma uma tentativa de resolver problemas que surjam na interação, focalizando brevemente a atenção em aspetos linguísticos.

No âmbito da escrita, o ELBT apresenta, pois, aspetos didáticos significativos (CASSANY, 2009) que o distingue de outras abordagens:

(1) Professor e alunos negoceiam as tarefas: durante o processo de planificação, são tomadas decisões sobre o que e a quem escrever (tipo de texto, assunto, destinatário) e sobre como escrever (tom, estilo, procedimentos). Não se trata apenas de decidir o que se vai escrever, mas também de se certificar de que as representações mentais de professor e aluno(s), construídas a partir de um mesmo contexto de escrita, são iguais ou semelhantes;

(2) Os alunos falam sobre o que escrevem: os alunos, quando justificam o que escreveram, verbalizam os seus pensamentos, apresentam as dificuldades 
que tiveram, permitindo que professor e colegas possam contribuir para o desenvolvimento da sua tarefa de escrita;

(3) Os rascunhos constituem uma fonte de informação: a análise das produções intermédias do texto permitem observar todo o trabalho de escrita dos alunos (a planificação do texto, as revisões, as dúvidas, etc.) até o produto final, valorizando-se assim todo o processo de escrita;

(4) O trabalho colaborativo é privilegiado: professor e alunos colaboram no trabalho de escrita durante todo o processo, com funções distintas. O professor ocupa o lugar de leitor especializado, que dá orientações aos alunos para que melhorem o texto. Os alunos podem ser coautores (em tarefas de pares ou pequenos grupos), leitores intermédios dos textos dos outros ou ainda destinatários (em tarefas cujo objetivo seja escrever um texto para os colegas);

(5) A avaliação centra-se no processo e no produto final: a avaliação do processo tem em conta as operações cognitivas e as atitudes dos alunos relativamente à escrita. A avaliação do produto final, por sua vez, avalia a competência escrita do aluno, incidindo na análise da qualidade linguística do texto.

Em suma, esta abordagem fomenta a negociação das tarefas entre professor e alunos; permite que os alunos estruturem o seu trabalho entendendo a escrita como um processo; promove tarefas de escrita durante as aulas, num ambiente dinâmico e interativo (interação com professor e colegas), num espírito colaborativo, em que todos contribuem para o sucesso comum; prevê uma reflexão permanente sobre o que aprenderam e sobre a correção com que usam a língua, levando os alunos a estabelecerem uma inter-relação sistemática entre a forma, o sentido e o uso.

\section{Descrição do estudo}

As características do tópico tratado levaram-nos a optar por um paradigma de investigação qualitativa, que nos pareceu ser congruente com o objeto da investigação. Optámos por este tipo de investigação por considerarmos que seria a mais adequada para perceber os processos, os produtos e os fenómenos inerentes à problemática deste estudo, a partir das observações e das perceções dos sujeitos envolvidos.

Dentro do paradigma da investigação qualitativa, usamos o enfoque etnográfico, para a recolha e análise dos dados, que se caracteriza por procurar compreender e interpretar os dados obtidos desde a perspetiva dos participantes na investigação. 
- O ensino de línguas baseado em tarefas no ensino/aprendizagem da escrita em português língua segunda - propostas didáticas

Optámos ainda por uma estratégia de estudo de caso, que nos permitiu observar e refletir sobre as práticas pedagógicas e o seu resultado na aprendizagem dos alunos e, ainda, a perceção que estes têm dele. Neste âmbito, mais do que os números, foram as palavras e as práticas que tomámos como objeto de análise, não deixando de recorrer, no entanto, à quantificação quando esta se tornou relevante para a compreensão de parte dos dados recolhidos.

O estudo que apresentamos neste artigo trata-se, pois, de um resultado parcial de uma investigação mais ampla que passou por diferentes fases. Iniciou-se com observação direta, não participante, de vinte e sete aulas de Língua Portuguesa ( $7^{\circ}$ ano) de nove professores, licenciados, de três escolas secundárias da cidade da Praia, com o objetivo de obter dados de objetivação no que diz respeito ao ensino da língua, focalizando particularmente o tipo de estratégias utilizadas pelos professores para promover o ensino da língua. Era nossa intenção compreender até que ponto essas estratégias se adequavam aos alunos cabo-verdianos para quem o português é uma L2.

Num segundo momento, procurámos verificar as competências de três dos nove docentes, envolvidos na primeira fase, na aplicação de estratégias de ensino da língua, que se adequassem à realidade cabo-verdiana. A fim de operacionalizarmos esta segunda etapa, elaborámos previamente um guião de estratégias para os professores e fichas de trabalho para os alunos. Seguidamente, realizámos sessões com os três professores envolvidos no estudo, com o objetivo de analisarmos em conjunto as propostas, esta abordagem, a exequibilidade do tipo de tarefas e a abordagem com foco na forma. O guião foi implementado ao longo de um mês.

No sentido de obtermos as posteriores reações dos professores, optámos pela entrevista semiestruturada, dado que os entrevistados tiveram a possibilidade de discorrer sobre suas experiências, a partir do foco principal proposto por nós.

Optámos ainda por realizar um questionário aos alunos das três turmas envolvidas, a fim de procurarmos conhecer as opiniões sobre a disciplina de língua portuguesa e as suas reações relativamente a esta nova forma de aprendizagem da língua, uma vez que não estavam habituados à mesma. Os dados obtidos e a respetiva análise possibilitaram-nos compreender o caso objeto de estudo, tendo em conta a sua validade, mas sem termos qualquer intenção de generalização estatística externa dos resultados.

Os participantes nas duas fases do estudo constituem uma amostragem não probabilística, de conveniência. No primeiro momento (observação de aulas), foram selecionados nove professores que lecionavam o $7^{\circ}$ ano de escolaridade, que se mostraram disponíveis em colaborar, sem quaisquer reservas. Destes nove, na segunda 
fase, foram selecionados três, um de cada escola (Escola Secundária Cónego Jacinto, Escola Secundária do Palmarejo e Liceu Domingos Ramos), que permaneciam como professores do $7^{\circ}$ ano. $\mathrm{O}$ único critério utilizado foi o de todos possuírem habilitações literárias superiores e condições de trabalho semelhantes. O número de alunos por turma variava entre os 33 na Escola Secundária Cónego Jacinto, os 37 da Escola Secundária do Palmarejo e os 34 no Liceu Domingos Ramos, pelo que o número total de alunos inquiridos foi 104.

\section{Tarefas de produção escrita: algumas propostas didáticas}

As propostas apresentadas a seguir integraram um leque de atividades desenvolvidas durante o estudo, à semelhança do que propõe Cabral (2004). Visavam integrar as quatro competências; desenvolver a produção escrita de forma multifacetada; melhorar de forma eficaz a aprendizagem da língua; ter consciência das dificuldades linguísticas quer pela interação aluno/aluno quer aluno/professor, compreendê-las e ultrapassá-las; aprender de forma colaborativa a construção do conhecimento.

(1) Tarefa: Cada personagem no seu espaço

- Pré-tarefa

Entregar aos alunos um pequeno texto narrativo e analisar com eles a forma como são introduzidas as personagens, como é feita a descrição espacial, marcado o tempo (narração vs. descrição)...

Distribuir aos alunos uma série de cartões de dois tipos diferentes e de histórias distintas: uns contêm dados descritivos e outros a indicação de uma personagem e verbos de ação. Exemplo: 
- O ensino de línguas baseado em tarefas no ensino/aprendizagem da escrita em português língua segunda - propostas didáticas

Figura 2. Cartões de atividade escrita

\begin{tabular}{|l|l|l|}
\hline \multicolumn{1}{|c|}{ Descrição } & \multicolumn{1}{c|}{ Narração } \\
\hline Noite sinistra & & Aparece uma jovem. \\
\hline Vento e chuva torrencial & & O carro avaria. \\
\hline Um castelo misterioso & & Caminha pela estrada. \\
\hline Porta que range & & Entra no castelo. \\
\hline Interior abandonado & & Sobe umas escadas. \\
\hline Ratos e teias de aranha & Grita. \\
\hline Música de órgão & \\
\hline
\end{tabular}

Fonte: Elaboração própria (adaptado de Sanz Pastor, 2006)

- Tarefa:

Inicialmente, cada aluno tem de encontrar o seu par, ou seja, outro aluno que possua os dados necessários compatíveis com a informação do seu cartão.

Encontrados os pares, os alunos vão escrever, a partir das informações que têm, o início de uma história no passado.

Após terminada a introdução da história, cada par apresenta-a à turma e ao professor e estes podem dar-lhes sugestões de melhoria e de continuação da história.

Os alunos regressam ao seu texto e continuam a história, aproveitando as sugestões dos colegas e do professor.

Após conclusão do texto, cada par lê a sua história à turma.

- Pós-tarefa

Foco na forma: o professor pode aproveitar o momento para fazer uma revisão do uso do Pretérito Perfeito vs. Pretérito Imperfeito, por exemplo.

Feedback e avaliação.

Entre todos pode-se ainda decidir qual é a história mais criativa. 
(2) Tarefa: Antevisão da história (A Galinha, de Vergílio Ferreira)

- Pré-tarefa:

Dividir a turma em grupos de quatro elementos.

Distribuir a cada grupo uma parte do texto e um cartão com informações, em forma de pistas, que orientam para as outras partes da história. Exemplo:

Grupo A: Algumas pistas para ajudar a prever o resto da história regresso separado dos familiares - mãe leva as duas galinhas - troca de galinhas - desentendimento

Grupo B: Algumas pistas para ajudar a prever o início e o fim da história ida de camioneta - feira - regatear - discussão entre os familiares

Grupo C: Algumas pistas para ajudar a prever o início e o desenvolvimento da história

ida à feira de camioneta - compra de duas galinhas - regresso de carroça e de camioneta - troca de galinhas

- Tarefa:

Os grupos vão preparar as suas histórias com base na parte do texto e nas pistas que receberam.

(Atribuir tempo suficiente para que todos os alunos possam participar na construção da história.)

Depois de construir a história, cada grupo elege um "embaixador", cujo papel é contactar os outros grupos. Este aluno deve preparar, com os outros alunos do grupo, o que vai dizer e perguntar aos outros grupos.

Cada "embaixador" circula pelos diferentes grupos, a fim de trocar informação sobre a história de cada um.

(Os grupos A não devem interagir com outros $A$, nem B com B ou C com C.)

Depois de concluída a ronda pelos diferentes grupos, cada "embaixador" 
- O ensino de línguas baseado em tarefas no ensino/aprendizagem da escrita em português língua segunda - propostas didáticas

regressa ao seu e analisam em conjunto a informação recolhida.

Os alunos concluem a sua história, fazendo os ajustes que considerarem necessários.

Após terminarem as suas histórias, leem-nas à turma; comparam-nas, observando semelhanças e diferenças.

O professor distribui o texto original e faz-se uma leitura do mesmo com o objetivo de comprovar se as histórias de cada grupo se aproximam da verdadeira ou não.

\section{- Pós-tarefa}

Foco na forma:

Solicitar aos alunos que sublinhem no texto todas as palavras que ajudam a encadear as diversas partes (os conetores).

Alguns exemplos possíveis:

depois... de repente... quando... então... agora...

Analisar com os alunos o tipo de conetores que encontraram. Fornecer mais alguns exemplos simples.

Realizar alguns exercícios breves (unir frases simples com conetores, completar lacunas em textos, substituir conetores num texto por outros de sentido equivalente...).

Feedback e avaliação.

Entre todos, decidem qual é a história que mais se aproxima da original.

Com este tipo de ensino da escrita em PL2, poder-se-á formar alunos capazes de comunicarem efetivamente na língua-alvo, usando-a de maneira contextualizada e autêntica, na sala de aula. As tarefas cujo resultado depende da troca de informação entre todos os elementos do grupo e entre grupos são mais efetivas, dado que envolvem uma responsabilidade repartida na distribuição de informação e no papel que cada um tem de desempenhar. Os alunos interagem com vista à compreensão mútua, à troca de opiniões, à obtenção de informação. Ora, esta interação coloca os alunos em exposição a um determinado input fornecido pelos restantes elementos da turma, bem como fomenta a produção de output quer durante o ato interativo quer na execução da tarefa de escrita propriamente dita. 


\section{Resultados parciais dos questionários aos alunos}

Os alunos participantes foram questionados sobre as suas reações ao ELBT. Foi nossa intenção ver de que modo esta nova forma de ensino, por tarefas, repercutiu nos alunos e na sua aprendizagem (interação com os colegas, com os materiais disponibilizados por nós e perceções sobre resultados dessa aprendizagem).

Os resultados dos questionários serão aqui descritos e analisados qualitativamente e sujeitos a uma análise comparativa para que possamos, por um lado, observar as semelhanças e diferenças entre as opiniões dos participantes e, por outro lado, compreender globalmente a sua reação relativamente às tarefas propostas durante o mês de experimentação.

Colocámos uma primeira questão para verificar que avaliação os alunos fizeram destas tarefas em comparação com as atividades que costumavam realizar anteriormente (cf. Tabela 1).

Tabela 1. Atividades mais interessantes

\begin{tabular}{l|l|r|r|r}
\hline \multirow{4}{*}{ Válidos } & & Freq. & \% & \% válida \\
\hline & Totalmente de acordo & 57 & 54,81 & 55,34 \\
\cline { 2 - 5 } & De acordo & 38 & 36,54 & 36,89 \\
\cline { 2 - 5 } & Indiferente & 7 & 6,73 & 6,80 \\
\cline { 2 - 5 } & Em desacordo & 1 & 0,96 & 0,97 \\
\cline { 2 - 5 } & Totalmente desacordo & 0 & 0,00 & 0,00 \\
\cline { 2 - 5 } & Total & 103 & 99,04 & 100,00 \\
\hline \multirow{2}{*}{ Sem resposta } & & 104 & 0,96 & \\
\hline \multicolumn{1}{|c|}{ Total } & & 100,00 & \\
\hline
\end{tabular}

Fonte: Elaboração própria

Através destes resultados, verificamos que as estratégias seguidas pelos professores durante o mês de experiência tiveram uma boa receção pela generalidade dos alunos, que as classificaram como mais interessantes do que aquelas a que estão habituados $(54,81 \%$ - Totalmente de acordo e 36,54\% - De acordo). Este facto está intimamente relacionado com o novo papel que passaram a desempenhar nas aulas de língua portuguesa e com o 
- O ensino de línguas baseado em tarefas no ensino/aprendizagem da escrita em português língua segunda - propostas didáticas

dinamismo das estratégias. Efetivamente, o ELBT permite que os alunos se tornem mais ativos, mais responsáveis pela construção do seu conhecimento, contrariando a tendência passiva a que são geralmente submetidos. Como refere Nunan (2004), ao recorrer-se a uma tarefa como uma unidade básica de aprendizagem, proporciona-se aos alunos a possibilidade de serem eles a planearem e a controlarem a sua própria aprendizagem, reduzindo a tendência para algumas hierarquias mais tradicionais em sala de aula.

As tarefas realizadas em grupo implicam uma constante partilha de ideias e de conhecimentos para que sejam concluídas satisfatoriamente. Neste sentido, uma das questões do questionário incidia sobre este aspeto (cf. Tabela 2).

Tabela 2. Partilha de conhecimentos entre alunos

\begin{tabular}{|c|c|c|c|c|}
\hline & & Freq. & $\%$ & \% válida \\
\hline \multirow{6}{*}{ Válidos } & Totalmente de acordo & 60 & 57,69 & 58,82 \\
\hline & De acordo & 28 & 26,92 & 27,45 \\
\hline & Indiferente & 9 & 8,65 & 8,82 \\
\hline & Em desacordo & 4 & 3,85 & 3,92 \\
\hline & Totalmente desacordo & 1 & 0,96 & 0,98 \\
\hline & Total & 102 & 98,08 & 100,00 \\
\hline \multicolumn{2}{|c|}{ Sem resposta } & 2 & 1,92 & \\
\hline \multicolumn{2}{|l|}{ Total } & 104 & 100,00 & \\
\hline
\end{tabular}

Fonte: Elaboração própria

Um dos aspetos positivos do ELBT é a possibilidade de os alunos trabalharem em grupo, desenvolvendo o seu trabalho com um objetivo comum, num espírito colaborativo. Como pudemos observar pelos dados do questionário, esta forma de aprendizagem agradou bastante aos alunos (57,69\% - Totalmente de acordo e 26,92\% - De acordo), pois permitiu-lhes interagir com os colegas com o intuito de criarem situações de aprendizagem, de construção de conhecimento. Os alunos, como uma equipa, trabalhando num sistema de colaboração, aperfeiçoarão a sua competência linguística e comunicativa e serão capazes de reproduzir em situações concretas de comunicação, fora da sala de aula, esses conhecimentos. O contexto da sala de aula, propício para este tipo de abordagem, caracteriza-se por ser dinâmico e colaborativo, com o intuito 
de se conseguir o envolvimento pessoal dos alunos com a língua segunda, através da realização de tarefas que permitam a cada aluno partilhar com os colegas as suas ideias e conhecimentos.

Um outro aspeto que procurámos aferir com este questionário foi o de compreender se, com estas novas estratégias usadas para o ensino, os alunos sentiram que melhoraram os seus resultados de aprendizagem da língua, nomeadamente, ao nível da escrita, se foram os mesmos ou se, pelo contrário, pioraram (cf. Tabela 3).

Tabela 3. Melhor uso da língua

\begin{tabular}{l|l|r|r|r}
\hline \multirow{4}{*}{ Válidos } & & Freq. & \% & \% válida \\
\hline & Totalmente de acordo & 48 & 46,15 & 46,15 \\
\cline { 2 - 5 } & De acordo & 35 & 33,65 & 33,65 \\
\cline { 2 - 5 } & Indiferente & 15 & 14,42 & 14,42 \\
\cline { 2 - 5 } & Em desacordo & 5 & 4,81 & 4,81 \\
\cline { 2 - 5 } & Totalmente desacordo & 1 & 0,96 & 0,96 \\
\cline { 2 - 5 } & Total & 104 & 100,00 & 100,00 \\
\hline \multirow{2}{*}{ Sem resposta } & & 104 & 0,00 & \\
\hline \multirow{2}{*}{ Total } & & & 100,00 & \\
\hline
\end{tabular}

Fonte: Elaboração própria

Os alunos foram claros nas suas respostas (Totalmente de acordo - 46,15\% e De acordo - 33,65\%), revelando que este ensino, que propicia a análise e a reflexão na língua e sobre a língua, em situações concretas de comunicação, facilita e melhora o seu uso, tornando-os mais proficientes na L2.

O desenvolvimento da competência comunicativa está relacionado com a capacidade de os alunos serem capazes de interpretar e usar um maior número de recursos linguísticos, quer no modo escrito quer no oral, de forma adequada em diversas situações de interação, sejam eles formais ou informais. Para um melhor uso da língua, os alunos devem ser capazes de refletir sobre diferentes aspetos em situações reais de comunicação, isto é, usar conhecimentos adquiridos através da prática e da análise linguística para expandir a sua capacidade de reflexão e aumentar a sua capacidade de usar a língua nas suas diferentes possibilidades de realização. 
- O ensino de línguas baseado em tarefas no ensino/aprendizagem da escrita em português língua segunda - propostas didáticas

\section{Conclusão}

O ELBT, no ensino de línguas segundas, permite recriar um contexto "natural" de aprendizagem dentro da sala de aula e proporcionar uma participação mais ativa dos alunos na realização das tarefas, num ambiente colaborativo, em que se promove a discussão e o diálogo entre alunos e alunos e professor. A maioria dos alunos participantes no estudo confirmou este princípio do ELBT ao responder muito favoravelmente ao trabalho colaborativo como um momento de partilha de conhecimentos. Neste ambiente de aprendizagem, o professor, por seu lado, não se limita a ser um instrutor, mas assume ainda o papel de um negociador, de um conselheiro, de um facilitador de conhecimentos, que deve ajudar os alunos durante a tarefa de escrita, tendo em vista o sucesso da tarefa.

Associado ao ELBT, o foco na forma possibilita ainda aos alunos, após várias reflexões, desenvolverem a sua consciência linguística e, consequentemente, a sua competência comunicativa. Este princípio do ELBT também ficou comprovado no questionário aplicado aos alunos, na medida em que a maioria considerou que esta forma de aprendizagem da escrita e da gramática facilita a sua concretização e promove um melhor conhecimento e uso da língua.

Nesta abordagem, a produção escrita pode ser trabalhada em sala de aula integrando diferentes competências comunicativas em língua e competências gerais. Os alunos podem escrever para aprender, para falar (produção e/ou interação) e podem ainda

refletir sobre o que escrevem ou para que escrevem. É, pois, uma abordagem que motiva os alunos e que os faz participar ativamente da sua aprendizagem. Como demonstrado, a maioria dos alunos participantes revelou que as tarefas realizadas durante o período do estudo eram mais interessantes do que aquelas que habitualmente realizavam.

Por fim, as tarefas de escrita propostas permitem que os alunos, durante a sua execução, interajam e façam uma reflexão sobre a tarefa em si, o que estimula o uso "real" da língua-alvo. Portanto, comparativamente a outras abordagens mais tradicionais, os resultados conseguidos com o ELBT, nas aulas de L2, confirmam a viabilidade e a importância da sua implementação. 


\section{Referências}

ATKINSON, D. L2 writing in the post-process era: Introduction. Journal of Second Language Writing, v. 1, n. 12, p. 3-16, 2003.

BRUTON, A. From tasking purposes to purposing tasks. ELT Journal, v. 56, n. 3, p. 280288, 2002a.

BRUTON, A. When and how the language development in TBI? ELT Journal, v. 56, n. 3, p. 296-297, 2002b.

BYGATE, M.; SKEHAN, P.; SWAIN, M. Researching Pedagogic Tasks: Second Language Learning, Teaching and Testing. Harlow, UK: Pearson Education, 2001.

CABRAL, M. Developing task-based writing with adolescent EFL students. The Internet TESL Journal, v. X, n. 2, fev. 2004. Disponível em: http://iteslj.org/Techniques/Cabal-TaskbasedWriting.html. Acesso em: 22 set. 2018.

CASSANY, D. La composición escrita en E/LE. marcoELE. Revista Didáctica del Español como Lengua Extranjera, v. 9, p. 47-66, 2009.

CONSELHO DA EUROPA. Quadro europeu comum de referência para as línguas: aprendizagem, ensino, avaliação. Porto: Asa, 2001.

ELLIS, R. Task-Based Language Learning and Teaching. Oxford: Oxford University Press, 2003.

ELLIS, R. Task-based language teaching: sorting out the misunderstandings. International Journal of Applied Linguistics, v. 19, n. 3, p. 221-246, 2009.

ELLIS, R. Taking the critics to tasks: the case for task-based teaching. In: AISHAH, M.; BHATT, S.; CHAN, W.; CHI, S.; CHIN, K.; KLAYKLUENG, S.; NAGAMI, M.; SEW, J.; SUTHIWAN, T.; WALKER, I. Knowledge, skills and competencies in foreign language education. Singapore: NUS Centre for Language Studies, 2014. p. 103-117. 
- O ensino de línguas baseado em tarefas no ensino/aprendizagem da escrita em português língua segunda - propostas didáticas

FOTOS, S. Structure-based interactive tasks for the EFL grammar learner. In: HINKEL, E.; FOTOS, S. New perspectives on grammar teaching in second language classrooms. New Jersey: Lawrence Erlbaum Associates, Publishers, 2002. p. 137-156.

KOHONEN, V. Experiential language learning: second language learning as cooperative learner education. In: NUNAN, D. Collaborative Language Learning and Teaching. Cambridge: Cambridge University Press, 1992. p. 37-56.

LARSEN-FREEMAN, D. Techniques and principles in language teaching. Oxford: Oxford University Press, 1986.

LONG, M. A role for instruction in second language acquisition: task-based language teaching. In: HYLTENSTAM, K.; PIENEMAN, M. Modelling and assessing second language acquisition. Clevedon: Multilingual Matters, 1985. p. 77-99.

LONG, M. Focus on Form: a design feature in language teaching methodology. In: DE BOT, K.; GINSBERG, R.; KRAMSCH, C. Foreign-Language Research in Cross-Cultural Perspective. Amsterdam: Benjamins, 1991. p. 39-52.

LONG, M. In defense of tasks and TBLT: Non-issues and real issues. Annual Review of Applied Linguistics, v. 36, p. 5-33, 2016.

LONG, M.; CROOKES, G. Three approaches to task-based syllabus design. TESOL Quarterly, v. 26, n. 1, p. 27-56, 1992.

LONG, M.; CROOKES, G. Units of Analysis in Syllabus Design: the Case for Task. In: G. CROOKES, G.; GASS, S. Tasks in Pedagogic Context: Integrating Theory and Practice. Clevedon: Multilingual Matters, 1993. p. 9-54.

LONG, M.; ROBINSON, P. Focus on form: theory, research, practice. In: DOUGHTY, C.; WILLIAMS, J. Focus on Form in Classroom Second Language Acquisition. Cambridge: Cambridge University Press, 1998. p. 15-63.

NUNAN, D. Designing tasks for the communicative classroom. Cambridge: Cambridge University Press, 1989. 
NUNAN, D. Task-Based Language Teaching. Cambridge: Cambridge University Press, 2004.

PICA, T. Subject matter content: How does it assist the interactional and linguistic needs of classroom language learners? The Modern Language Journal, v. 86, n. 1, p. 1-19, 2002.

PICA, T.; KANAGY, R.; FALODUN, J. Choosing and using communication tasks for second language research and instruction. In: CROOKES, G.; GASS, S. Tasks in a Pedagogical Context: Integrating Theory and Practice. Clevedon: Multilingual Matters, 1993. p. 9-34.

PRABHU, N. Second Language Pedagogy. Oxford: Oxford University Press, 1987.

RICHARDS, J.; RODGERS, T. Approaches and Methods in Language Teaching. Cambridge: Cambridge University Press, 2001.

SANZ PASTOR, M. Cada personage en su ambiente. In: HIGUERAS, G. M. Didactired. Actividades de la lengua y estrategias (comprensión, expressión, interacción y mediación). Madrid: Ediciones SM, 2006.

SEEDHOUSE, P. Task-based interaction. ELT Journal, v. 53, n. 3, p. 149-156, 1999.

SEEDHOUSE, P. "Task" as research construct. Language Learning, v. 55, n. 3, p. 533-570, 2005.

SHEEN, R. A critical analysis of the advocacy of the task-based syllabus. TESOL Quarterly, v. 28, p. 127-157, 1994.

SKEHAN, P. A Framework for the Implementation of Task-based Learning. Thames Valley University Working Papers in English Language Teaching, v. 3, p. 38-62, 1994.

SKEHAN, P. A Cognitive Approach to Language Learning. Oxford: Oxford University Press, 1998.

SWAN, M. Legislation by hypothesis: The case of task-based instruction. Applied Linguistics, v. 26, n. 3, p. 376-401, 2005. 
- O ensino de línguas baseado em tarefas no ensino/aprendizagem da escrita em português língua segunda - propostas didáticas

WIDDOWSON, H. Defining issues in English language teaching. Oxford: Oxford University Press, 2003.

WILLIS, D.; WILLIS, J. Doing Task-based Teaching. Oxford: Oxford University Press, 2007.

WILLIS, J. A framework for task-based learning. Harlow: Longman, 1996.

VAN THIENEN, K. Une approche basée sur la tâche. Encuentro - Revista de investigación e innovación en la clase de idiomas, v. 18, p. 60-66, 2009. Disponível em: http://www.encuentrojournal.org/textos/Van\%20Thienen_1.pdf. Acesso em: 16 set. 2018.

\section{Agradecimentos}

O autor agradece o apoio financeiro da Fundação para a Ciência e a Tecnologia (UIDB/00214/2020).

COMO CITAR ESTE ARTIGO: PINTO, Jorge. O ensino de línguas baseado em tarefas no ensino/aprendizagem da escrita em português língua segunda propostas didáticas. Revista do GEL, v. 17, n. 2, p. 170-195, 2020. Disponível em: https://revistadogel.gel.org.br/

DOI: http://dx.doi.org/10.21165/gel.v17i2.2425

Submetido em: 19/12/2018 | Aceito em: 23/06/2020. 